\title{
Zonal Momentum Balance in the Tropical Atmospheric Circulation during the Global Monsoon Mature Months
}

\author{
Wenchang Yang, Richard Seager, And Mark A. CAne \\ Lamont-Doherty Earth Observatory, Columbia University, Palisades, New York
}

(Manuscript received 7 May 2012, in final form 18 July 2012)

\begin{abstract}
In this paper, zonal momentum balances of the tropical atmospheric circulation during the global monsoon mature months (January and July) are analyzed in three dimensions based on the ECMWF Interim ReAnalysis (ERA-Interim). It is found that the dominant terms in the balance of the atmospheric boundary layer (ABL) in both months are the pressure gradient force, the Coriolis force, and friction. The nonlinear advection term plays a significant role only in the Asian summer monsoon regions within the ABL. In the upper troposphere, the pressure gradient force, the Coriolis force, and the nonlinear advection are the dominant terms. The transient eddy force and the residual force (which can be explained as convective momentum transfer over open oceans) are secondary, yet cannot be neglected near the equator. Zonal-mean equatorial upper-troposphere easterlies are maintained by the absolute angular momentum advection associated with the cross-equatorial Hadley circulation. Equatorial upper-troposphere easterlies over the Asian monsoon regions are also controlled by the absolute angular momentum advection but are mainly maintained by the pressure gradient force in January. The equivalent linear Rayleigh friction, which is widely applied in simple tropical models, is calculated and the corresponding spatial distribution of the local coefficient and damping time scale are estimated from the linear regression. It is found that the linear momentum model is in general capable of crudely describing the tropical atmospheric circulation dynamics, yet the caveat should be kept in mind that the friction coefficient is not uniformly distributed and is even negative in some regions.
\end{abstract}

\section{Introduction}

Since its introduction by Matsuno (1966), the equatorial beta-plane linear model has been serving as a simple dynamical framework for simulating the tropical circulation (Gill 1980; Davey and Gill 1987; Seager 1991). Most of these works assume that the total troposphere can be approximated by the single first baroclinic mode in the vertical such that the shallow water equations can be used to represent the dynamics driven by middletroposphere heating. Lindzen and Nigam (1987) used a different approach that only considers the dynamics of the atmospheric boundary layer (ABL) driven by the pressure gradients because of sea surface temperature gradients but this too yielded a set of shallow-water equations with dynamics equivalent to that of the first baroclinic mode method (Neelin 1989). Later works combined these

Corresponding author address: Wenchang Yang, Lamont-Doherty Earth Observatory, Columbia University, 61 Route 9W, Palisades, NY 10964.

E-mail: wyang@ldeo.columbia.edu two ideas to construct a new model structure with an $\mathrm{ABL}$ at the bottom plus a first baroclinic mode of the free troposphere above (Wang and Li 1993; Fu and Wang 1999).

Despite the success in simulating the general features of the tropical circulation, this type of simple tropical atmospheric circulation model has been challenged because the nonlinear advection terms have been totally ignored and large Rayleigh friction coefficients have to be applied in order to obtain realistic simulations. Diagnostics of the observational circulation confirmed the suitability of a linear approximation of the surface wind momentum dynamics (Zebiak 1990; Deser 1993), although the Rayleigh friction coefficients were demonstrated to be latitude dependent and have different magnitudes for zonal and meridional winds (Deser 1993; Chiang and Zebiak 2000). Recent studies (Lin et al. 2008) revealed the potential sources of the strong Rayleigh friction over different regions within the Walker circulation: in the deep convection region (the western branch of the Walker circulation), both nonlinear advection and convective momentum transfer (CMT) contribute 
in the upper troposphere as well as in the lower troposphere; in the shallow convection region (the eastern branch of the Walker circulation), the nonlinear advection contributes in the upper troposphere while the CMT only contributes in the lower troposphere. However, Lin et al. (2008) focused on the zonal momentum balance in the longitude-pressure cross section near the equator instead of the whole tropics and only the annual mean circulation was investigated.

Another issue relevant to the zonal momentum budget is how the equatorial upper-troposphere zonal winds are maintained. In their explanation of why the climatological zonal winds are dominated by easterlies in the equatorial upper troposphere, Lee (1999) challenged the idea that they are maintained by the momentum flux divergence of the midlatitude-generated synoptic eddies (Suarez and Duffy 1992) and proposed that the easterlies are maintained by the transient zonal-mean meridional circulation associated with the seasonal cycle of the Hadley circulation and decelerated by tropical transient eddies with intraseasonal, intraannual, and interannual time scales. GCM studies also showed that the easterlies in the equatorial upper troposphere are driven by the cross-equatorial mean meridional circulation while the tropical eddies tend to decelerate them (Kraucunas and Hartmann 2005). Dima et al. (2005) conducted a systematic investigation on the tropical zonal-mean zonal momentum balance based on the National Centers for Environmental Prediction-National Center for Atmospheric Research (NCEP-NCAR) reanalysis dataset and confirmed the ideas in Lee (1999) and Kraucunas and Hartmann (2005). However, only the global zonal-mean circulations have been examined in these studies and the zonal asymmetry has not been considered. This is important because tropical uppertroposphere easterlies are not uniformly distributed in the zonal direction and westerlies can dominate under some conditions (e.g., over the eastern Pacific during boreal winter). It is interesting to examine if the easterly maintenance mechanism for the global zonal-mean flow can be extended to local longitudes and, in contrast, what mechanism is responsible for the maintenance of local westerlies at other longitudes.

In this paper we will examine the zonal momentum balances of the tropical atmospheric circulation in January (which represents the peak of the Southern Hemisphere monsoon) and July (which represents the peak of the Northern Hemisphere monsoon) in three dimensions based on the European Centre for Medium-Range Weather Forecasts (ECMWF) Interim Re-Analysis (ERAInterim). We will extend the study of annual mean momentum balance near the equator by Lin et al. (2008) to the momentum balance in particular months (January and July) and throughout the tropics. Our study also goes beyond the work of Lee (1999), Dima et al. (2005), and Kraucunas and Hartmann (2005) by considering the longitudinal asymmetry-that is, the zonal distribution of zonal momentum. The key questions to be answered include the following: What are the dominant terms in the tropical zonal momentum balance? How good is the linear dynamics approximation for the zonal momentum equation in the widely used simple tropical atmospheric models? Which mechanism is responsible for the maintenance of the dominant easterlies in the equatorial upper troposphere in the regions where they exist? What are the differences in the zonal momentum budget between January and July? The paper is organized as follows: Data and methods are described in section 2. Section 3 analyzes the zonal momentum balance on $925 \mathrm{hPa}$ (which represents the atmospheric boundary layer) and $200 \mathrm{hPa}$ (which represents the upper troposphere). Section 4 investigates the zonal momentum balance near the equator, where the Coriolis force approaches zero. Both the zonal-mean and locally longitudinal-mean momentum balance are examined in section 5. Section 6 estimates the equivalent Rayleigh friction both in the atmospheric boundary layer and the upper free troposphere. The conclusions are given in section 7 .

\section{Data and methods}

The daily versions of ERA-Interim data (Dee et al. 2011) in January and July from 1979 to 2010 are used in the zonal momentum balance analysis. The spatial resolution is $1.5^{\circ}$ longitude by $1.5^{\circ}$ latitude.

The zonal momentum equation in pressure coordinates can be can be obtained by applying the multiple-year monthly mean to Eq. (2) of Lin et al. (2008):

$$
\begin{aligned}
\frac{\partial \bar{u}}{\partial t}= & -\left(\bar{u} \frac{\partial \bar{u}}{\partial x}+\bar{v} \frac{\partial \bar{u}}{\partial y}+\bar{\omega} \frac{\partial \bar{u}}{\partial p}\right)-\frac{\partial \bar{\phi}}{\partial x}+f \bar{v} \\
& -\left(\frac{\partial \overline{u^{\prime} u^{\prime}}}{\partial x}+\frac{\partial \overline{u^{\prime} v^{\prime}}}{\partial y}+\frac{\partial \overline{u^{\prime} \omega^{\prime}}}{\partial p}\right)+X,
\end{aligned}
$$

where $u, v, \phi$, and $f$ are zonal velocity, meridional velocity, geopotential, and the Coriolis parameter, respectively; the bar denotes the multiple-year mean of the daily data in a specific month (in the case of this paper, January or July); and the prime denotes the daily deviation from the multiple-year monthly mean. In the multiple-year monthly mean momentum balance equation (1), the term on the left-hand side can be neglected, the term $-(\bar{u} \partial \bar{u} / \partial x+\bar{v} \partial \bar{u} / \partial y+\bar{\omega} \partial \bar{u} / \partial p)$ is the nonlinear advection by the stationary flow and the term $-\left(\partial \overline{u^{\prime} u^{\prime}} / \partial x+\right.$ $\left.\partial \overline{u^{\prime} v^{\prime}} / \partial y+\partial \overline{u^{\prime} \omega^{\prime}} / \partial p\right)$ is the nonlinear transient eddy 
(a)Tropical oceans, Jan
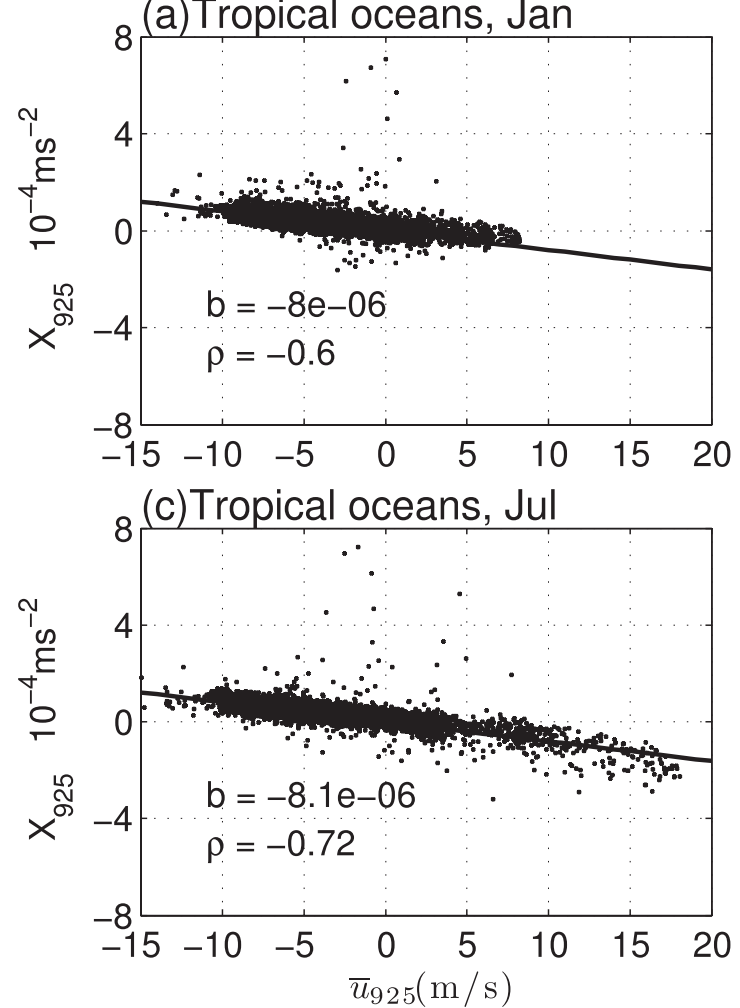

(b) Tropical lands, Jan
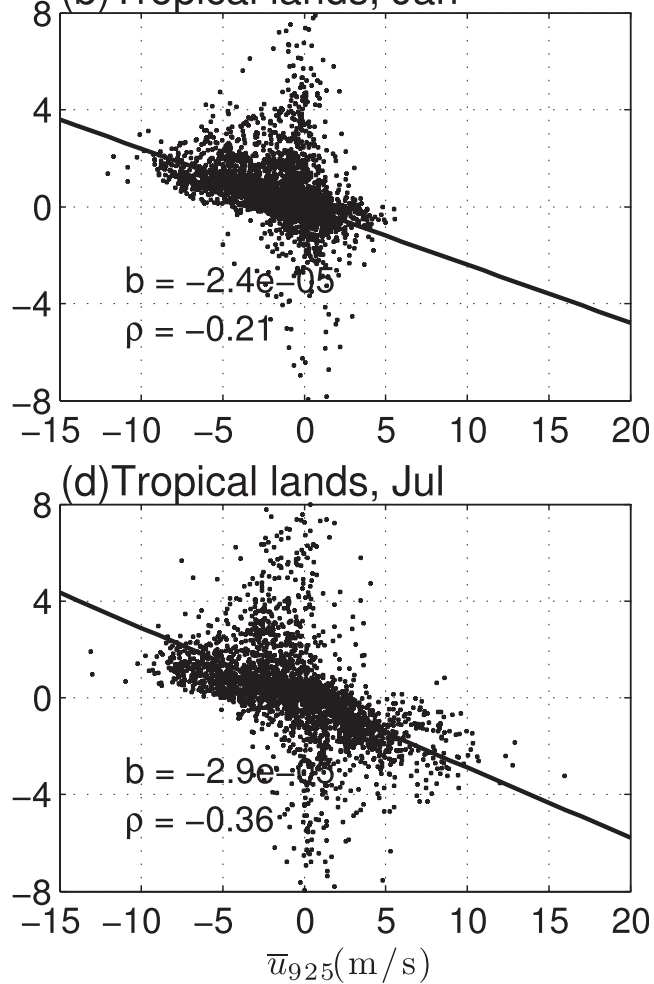

FIG. 1. Scatterplot of $X$ vs $\bar{u}$ at $925 \mathrm{hPa}$ over tropical oceans and tropical lands (between $30^{\circ} \mathrm{N}$ and $30^{\circ} \mathrm{S}$ ) in January and July. Each point in the scatterplot corresponds to a grid point at the 925 -hPa level. Variables $\rho$ and $b$ indicate the correlation coefficient and the regression coefficient (based on regression model $\hat{X}=b \bar{u}$ ), respectively.

force, $-\partial \bar{\phi} / \partial x$ is the pressure gradient force and $f \bar{v}$ is the Coriolis force, and $X$ represents all of the forces from the unresolved subgrid scale and possibly errors involved in the estimation process and data themselves.

What kind of force is dominant within $X$ ? In the ABL, $X$ is expected to be dominated by friction induced by turbulence and can be parameterized reasonably well by Rayleigh friction (Zebiak 1990; Deser 1993). The scatterplots of $X$ versus $\bar{u}$ at all grid points at $925 \mathrm{hPa}$ in Fig. 1 show that there is a negative correlation between the residual term and the zonal velocity. The correlation coefficients have little difference between January and July but are larger over the oceans than over lands. Also, the Rayleigh friction coefficients (the negative of the regression coefficients) are 3-4 times larger over lands than over oceans, indicating much stronger frictions over lands due to the rougher surface. Figures 2 and 3 show the Rayleigh friction estimate of $X$ with the mean zonal velocity $\bar{u}$ at $925 \mathrm{hPa}$, using different regression coefficients for the oceans and land, as shown in Fig. 1. The regressions account for the majority of $X$ over the oceans in both January and July. Over the lands, however, the regression does not perform as well, reflecting the inhomogeneity of surface roughness, which makes it difficult of using a uniform Rayleigh friction coefficient.

In the free troposphere over the open ocean, Carr and Bretherton (2001) and Lin et al. (2008) demonstrated that $X$ is dominated by the CMT. As argued in Lin et al. (2008), CMT can be approximated by

$$
\mathrm{CMT} \approx \delta_{c}\left(u_{b}-u\right)
$$

where $\delta_{c}$ is the cloud detrainment rate, $u_{b}$ is the zonal wind at cloud base, and $u$ is the zonal wind in the free troposphere. By assuming $\delta_{c}$ is proportional to precipitation rate and choosing the cloud base approximately at $925 \mathrm{hPa}$, the CMT can be expressed as

$$
\mathrm{CMT} \approx b \times P \times\left(u_{925}-u\right),
$$

where $P$ is the precipitation rate and $b$ is the coefficient relating $\delta_{c}$ and $P$. Figure 4 shows the relation between $X$ (colors) and prcp $\times\left(\bar{u}_{925}-\bar{u}_{200}\right)$ (contours) at $200 \mathrm{hPa}$. The total precipitation in the ERA-Interim dataset is 


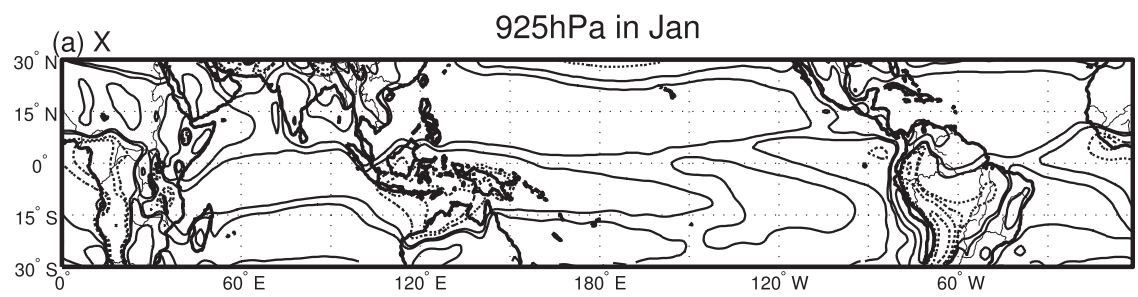

(b) $X_{r e g}$

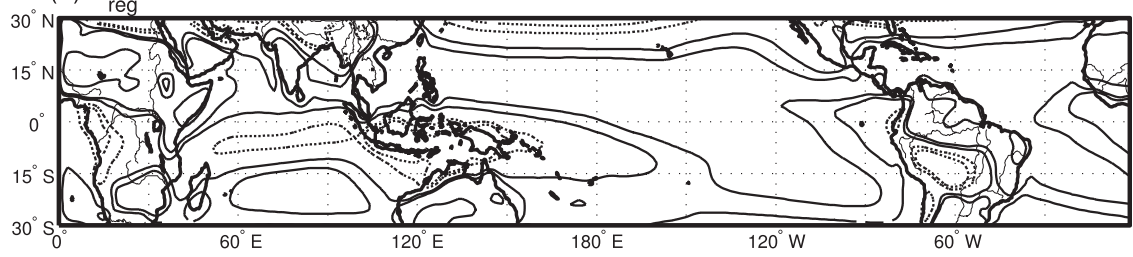

(c) $\mathrm{X}-\mathrm{X}_{\mathrm{reg}}$

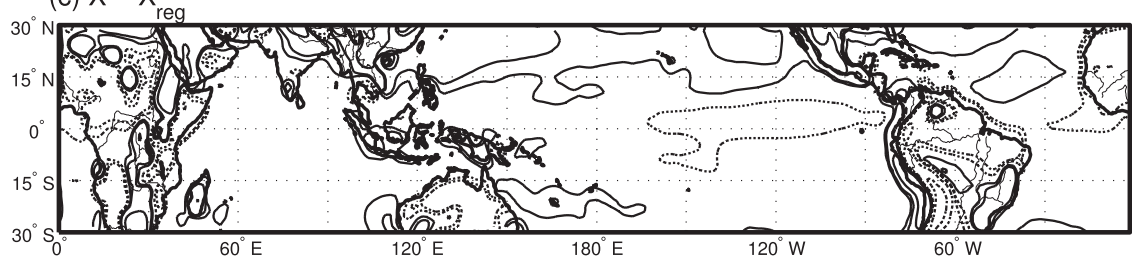

FIG. 2. Regression of $X$ by $\bar{u}$ at $925 \mathrm{hPa}$ in January. (a) The residual term $X$. (b) The regression of $X$. (c) The difference between $X$ and its regression. The contour values are $(-6.4$, $-1.6,-0.4,-0.2,0.2,0.4,1.6,6.4) \times 10^{-4} \mathrm{~m} \mathrm{~s}^{-2}$. Solid and dashed lines represent positive and negative values, respectively. To focus on large-scale features, the traditional 1-2-1 low-pass filter is applied twice in both dimensions for each contour field.

used here. The precipitation from version 2.2 of the National Aeronautics and Space Administration (NASA) Global Precipitation Climatology Project (GPCP) (Adler et al. 2003; Huffman et al. 2009) was also used for this calculation, but the results are not shown here as they are not significantly different from those using the ERAInterim precipitation. In both January and July, these two terms have a qualitative spatial relationship with each other, indicating that at least part of the residual term $X$ can indeed be explained by CMT in the free troposphere. To quantify the relationship between these two terms, scatterplots and regression analysis are performed on the grid points over the oceans (Figs. 4c and e) and over the lands (Figs. 4d and f) separately. It is found that the spatial correlation between $X$ and the estimated CMT behaves differently between oceans and lands. While the correlation coefficients over the oceans have much higher values (0.37 in January and 0.19 in July), they are much weaker and even negative over lands, which is consistent with what has been pointed out in Carr and Bretherton (2001) and Lin et al. (2008) that CMT dominates the residual of the momentum budget only over open oceans in the free troposphere. It should also be mentioned here that the estimated CMT is quantitatively only able to account less than half of the whole residual term even over the oceans, reflecting either the crudeness of the representation of the cloud detrainment rate by the precipitation rate or the contamination of $X$ by other sources (e.g., gravity wave activities and errors of data itself).

The longitudinal-mean (i.e., average between two specific longitudes) version of the momentum balance equation above can be written as

$$
\begin{aligned}
\frac{\partial[\bar{u}]}{\partial t}= & -\left[\bar{u} \frac{\partial \bar{u}}{\partial x}+\bar{v} \frac{\partial \bar{u}}{\partial y}+\bar{\omega} \frac{\partial \bar{u}}{\partial p}\right]-\frac{\partial[\bar{\phi}]}{\partial x}+f[\bar{v}] \\
& -\left[\frac{\partial \overline{u^{\prime} u^{\prime}}}{\partial x}+\frac{\partial \overline{u^{\prime} v^{\prime}}}{\partial y}+\frac{\partial \overline{u^{\prime} \omega^{\prime}}}{\partial p}\right]+[X] \\
= & -\left([\bar{u}] \frac{\partial[\bar{u}]}{\partial x}+[\bar{v}] \frac{\partial[\bar{u}]}{\partial y}+[\bar{\omega}] \frac{\partial[\bar{u}]}{\partial p}\right) \\
& -\left[\bar{u}^{*} \frac{\partial \bar{u}^{*}}{\partial x}+\bar{v}^{*} \frac{\partial \bar{u}^{*}}{\partial y}+\bar{\omega}^{*} \frac{\partial \bar{u}^{*}}{\partial p}\right]-\frac{\partial[\bar{\phi}]}{\partial x}+f[\bar{v}] \\
& -\left[\frac{\partial \overline{u^{\prime} u^{\prime}}}{\partial x}+\frac{\partial \overline{u^{\prime} v^{\prime}}}{\partial y}+\frac{\partial \overline{u^{\prime} \omega^{\prime}}}{\partial p}\right]+[X],
\end{aligned}
$$

where the square brackets denote the longitudinal mean and the asterisks denote the deviation from the longitudinal mean. The term $-([\bar{u}] \partial[\bar{u}] / \partial x+[\bar{v}] \partial[\bar{u}] / \partial y+[\bar{\omega}] \partial[\bar{u}] / \partial p)$ represents the forcing from the longitudinal-mean stationary flow while $-\left[\bar{u}^{*} \partial \bar{u}^{*} / \partial x+\bar{v}^{*} \partial \bar{u}^{*} / \partial y+\bar{\omega}^{*} \partial \bar{u}^{*} /\right.$ 


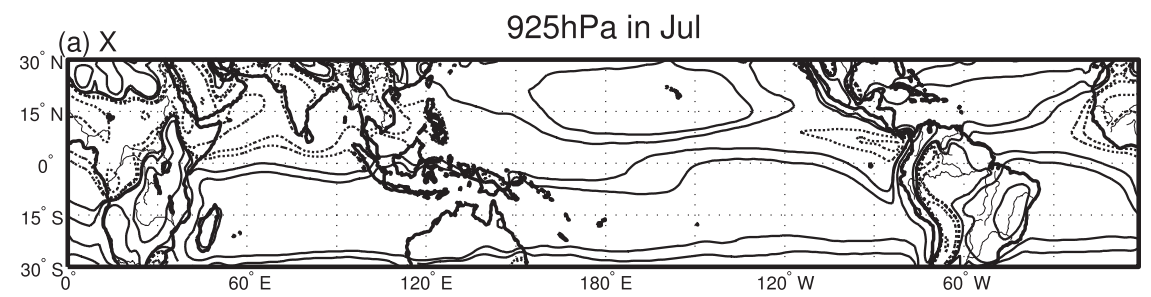

(b) $X_{r e g}$

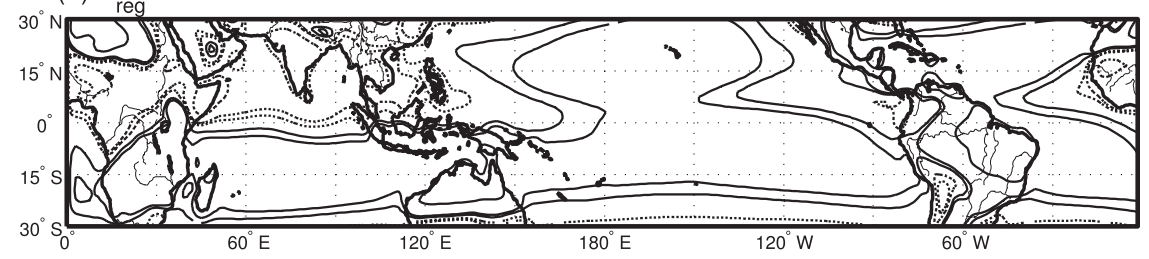

(c) $X-X_{\text {reg }}$

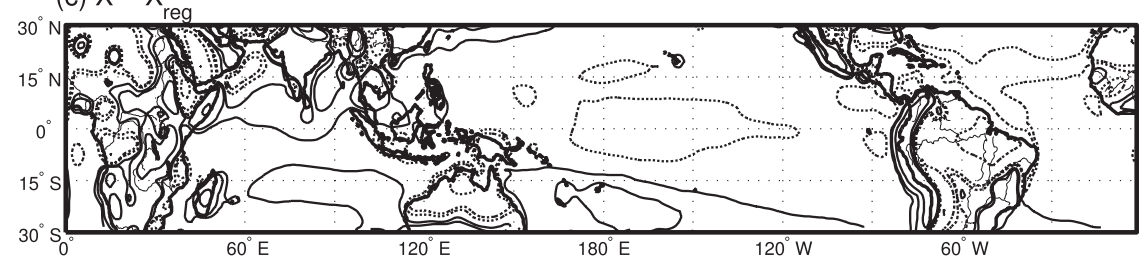

FIG. 3. As in Fig. 2, but for July.

$\partial p]$ represents the forcing from the stationary eddies. If the longitudinal mean is taken over all longitudes, the traditional zonal-mean version of the momentum balance equation can be simplified as

$$
\begin{aligned}
\frac{\partial[\bar{u}]}{\partial t}= & -\left[\bar{v} \frac{\partial \bar{u}}{\partial y}+\bar{\omega} \frac{\partial \bar{u}}{\partial p}\right]+f[\bar{v}]-\left[\frac{\partial \overline{u^{\prime} v^{\prime}}}{\partial y}+\frac{\partial \overline{u^{\prime} \omega^{\prime}}}{\partial p}\right]+[X] \\
= & -\left([\bar{v}] \frac{\partial[\bar{u}]}{\partial y}+[\bar{\omega}] \frac{\partial[\bar{u}]}{\partial p}\right)-\left[\bar{v}^{*} \frac{\partial \bar{u}^{*}}{\partial y}+\bar{\omega}^{*} \frac{\partial \bar{u}^{*}}{\partial p}\right] \\
& +f[\bar{v}]-\left[\frac{\partial \overline{u^{\prime} v^{\prime}}}{\partial y}+\frac{\partial \overline{u^{\prime} \omega^{\prime}}}{\partial p}\right]+[X] .
\end{aligned}
$$

In many simple tropical dynamics models, the momentum equations are approximated by linear dynamics; that is, keep only the pressure gradient force and Coriolis force on the right-hand side of Eq. (1) and parameterize the total effect of all the other terms on the right-hand side of Eq. (1) with Rayleigh friction. In this case, the linear version of the zonal momentum equation (1) becomes

$$
\frac{\partial \bar{u}}{\partial t}=-\frac{\partial \bar{\phi}}{\partial x}+f \bar{v}-\epsilon \bar{u},
$$

where $\epsilon$ is the friction coefficient. As the monthly means of the pressure gradients, zonal winds, and meridional winds over multiple years can be obtained from the reanalysis data, we can estimate the equivalent Rayleigh friction coefficients on each grid point by using linear regression.

\section{Zonal momentum balance on pressure levels}

Figure 5 shows the right-hand-side terms in the zonal momentum equatoin (1) in January at the 925-hPa level. It can be seen from Fig. 5 that the zonal momentum balance in the $\mathrm{ABL}$ is among three dominant terms: the pressure gradient force (Fig. 5a), the Coriolis force (Fig. $5 \mathrm{~b}$ ), and the residual term, which is here primarily surface friction (Fig. 5e). One measure of the overall magnitude of each term over the two-dimensional grids is the root-mean-square (RMS) value. The calculations show that the RMS values for the pressure gradient force and the Coriolis force are both $1.1 \times 10^{-4} \mathrm{~m} \mathrm{~s}^{-2}$ and the value of the residual force is $9.8 \times 10^{-5} \mathrm{~m} \mathrm{~s}^{-2}$, indicating that the magnitudes of the three dominant terms are of the same order. The RMS value of the nonlinear advection term is only $1.4 \times 10^{-5} \mathrm{~m} \mathrm{~s}^{-2}$ and the eddy forcing is even smaller, with an RMS value of $6.5 \times 10^{-6} \mathrm{~m} \mathrm{~s}^{-2}$.

In July, the zonal momentum balance at the $925-\mathrm{hPa}$ level (Fig. 6) shares similar features with that in January. In general, the dominant terms are still the same: the pressure gradient force (Fig. 6a), the Coriolis force (Fig. 6b), and the friction (Fig. 6e), with RMS values of $1.3 \times 10^{-4}, 1.2 \times 10^{-4}$, and $1.1 \times 10^{-5} \mathrm{~m} \mathrm{~s}^{-2}$, respectively. The magnitude of the transient eddy force (Fig. 6d) is 

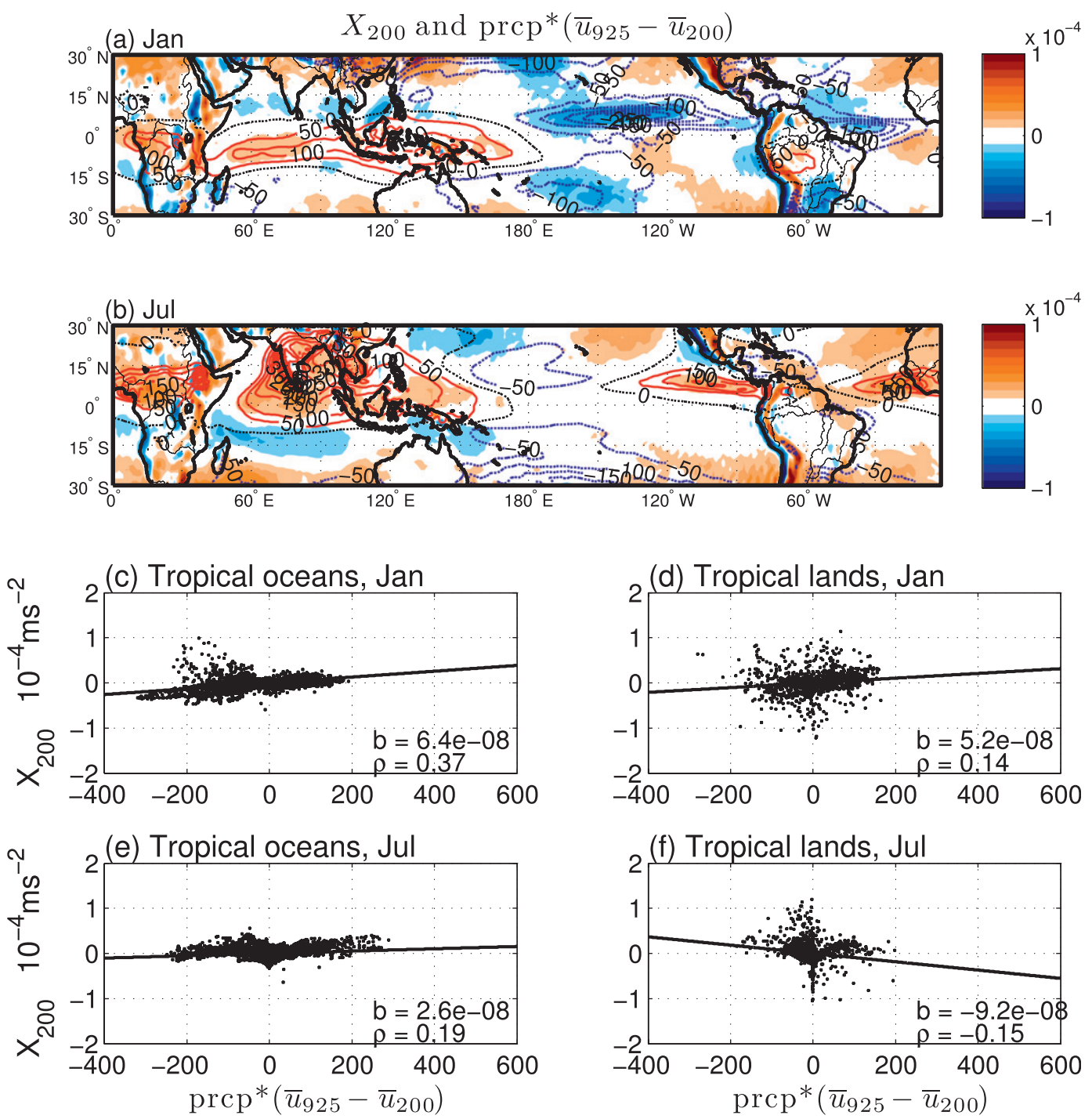

FIG. 4. The residual term (colors; $\mathrm{m} \mathrm{s}^{-2}$ ) and $\operatorname{prcp} \times\left(\bar{u}_{925}-\bar{u}_{200}\right)$ (contours; $\mathrm{mm} \mathrm{day}^{-1} \mathrm{~m} \mathrm{~s}^{-1}$ ) at $200 \mathrm{hPa}$ in (a) January and (b) July. (c)-(f) The scatterplots of $X$ vs prcp $\times\left(\bar{u}_{925}-\bar{u}_{200}\right)$ over tropical oceans in January, tropical lands in January, tropical oceans in July, and tropical lands in July, respectively. Only grid points with precipitation rate greater than $2 \mathrm{~mm} \mathrm{day}^{-1}$ are used. The variable $\rho$ is the correlation coefficient between $X$ and $\operatorname{prcp} \times\left(\bar{u}_{925}-\bar{u}_{200}\right)$ and $b$ is the regression coefficient when the regression model $\hat{X}=b \times \operatorname{prcp} \times\left(\bar{u}_{925}-\bar{u}_{200}\right)$ is used.

again one order weaker than those of the dominant terms. The nonlinear advection term (Fig. 6c) is in general much weaker than those dominant terms, indicated by the much smaller RMS value of $2.1 \times 10^{-5} \mathrm{~m} \mathrm{~s}^{-2}$. However, the nonlinear advection by the stationary flow has comparable magnitudes with those of the dominant terms in the Asian monsoon regions, especially near the Somali jet. This implies that the large-scale Asian summer monsoon circulation is nonlinear even in the ABL.

Figure 7 shows the zonal momentum balance of the multiple-year mean January flow at the 200-hPa level. Similar to the ABL case, the pressure gradient force (Fig. 7a) and the Coriolis force (Fig. 7b) are the dominant terms in the zonal momentum balance, with RMS values of $1.5 \times 10^{-4}$ and $2.2 \times 10^{-4} \mathrm{~m} \mathrm{~s}^{-2}$, respectively. However, unlike the boundary layer cases, the residual force is no longer among the dominant forces everywhere with an RMS value of only $1.4 \times$ $10^{-5} \mathrm{~m} \mathrm{~s}^{-2}$-almost one order smaller than those of the dominant terms. Instead, the nonlinear advection term joins the dominant terms group, with an RMS value of $1.1 \times 10^{-4} \mathrm{~m} \mathrm{~s}^{-2}$. The transient eddy force is as weak as the residual force in magnitude. In July, the boundary between the dominant terms and the minor terms is not as clear as in January. The top two forces in magnitude are the Coriolis force (Fig. 8b) and the 

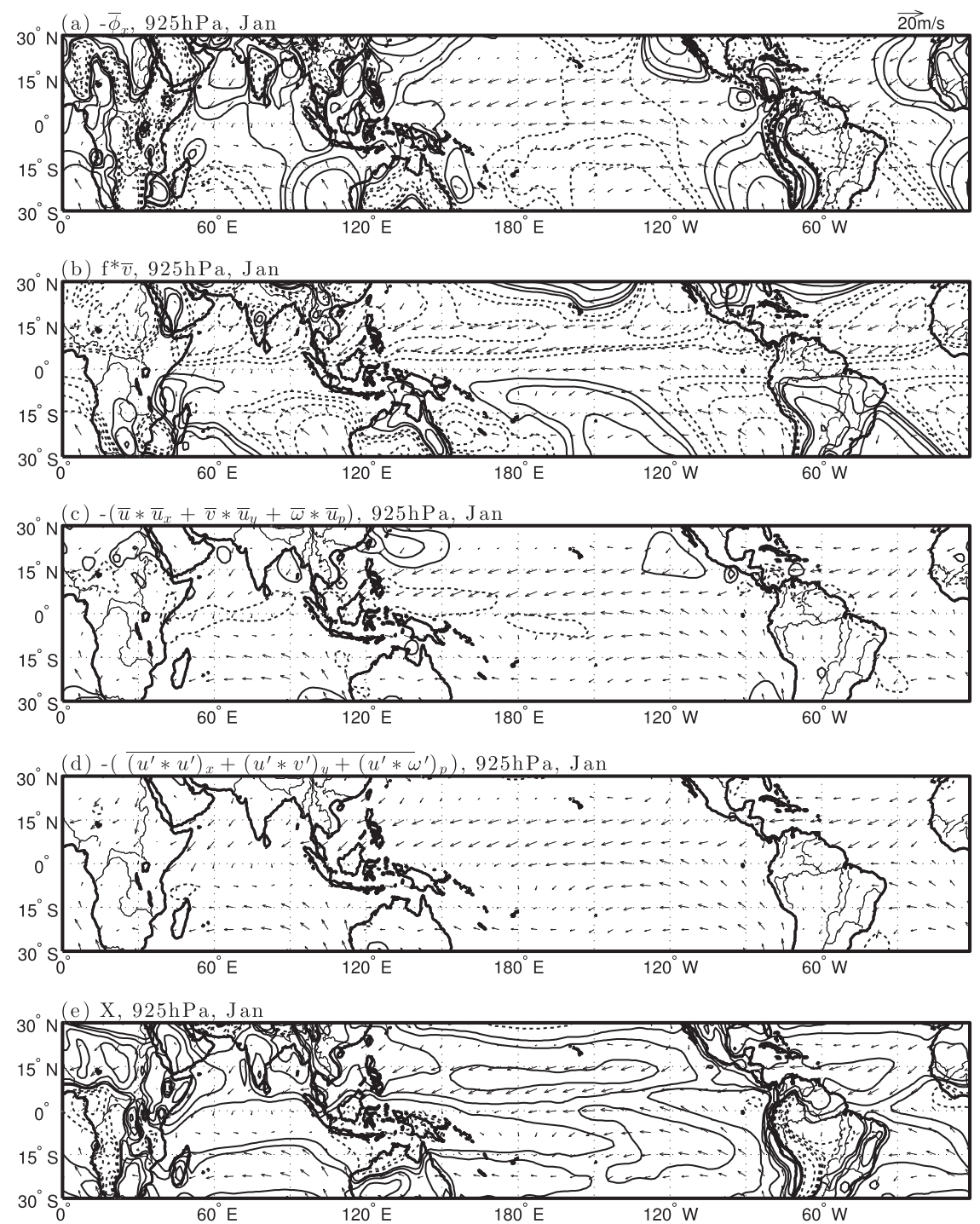

FIG. 5. Multiple-year mean January zonal momentum budget at the 925-hPa level (contours). The contour values are $(-6.4,-1.6,-0.8,-0.4,-0.2,0.2,0.4,0.8,1.6,6.4) \times 10^{-4} \mathrm{~m} \mathrm{~s}^{-2}$. Solid and dashed lines represent positive and negative values, respectively. Vectors denote winds at the pressure level. To focus on large-scale features, the traditional 1-2-1 low-pass filter is applied twice in both dimensions for each contour field.

pressure gradient force (Fig. 8a), with RMS values of $1.3 \times 10^{-4}$ and $9.6 \times 10^{-5} \mathrm{~m} \mathrm{~s}^{-2}$, respectively. The bottom two forces in magnitude are the transient eddy force (Fig. 8d) and the residual force (Fig. 8e), with RMS values of $2.2 \times 10^{-5}$ and $1.4 \times 10^{-5} \mathrm{~m} \mathrm{~s}^{-2}$, respectively. The nonlinear advection term (Fig. 8c) lies just between the two extremes, with an RMS value of $7.0 \times 10^{-5} \mathrm{~m} \mathrm{~s}^{-2}$. So approximately, the zonal momentum balance at $200 \mathrm{hPa}$ in July is among the pressure gradient force, the Coriolis force, and the nonlinear advection term. The transient eddy force and the residual force can in general be neglected.

\section{Zonal momentum balance near the equator}

The results in the above section show that, in both the atmospheric boundary layer and the upper-level troposphere, the Coriolis force is among the dominant terms in the zonal momentum balance. However, the Coriolis force will almost disappear near the equator no matter how strong the meridional flow is. Therefore the zonal momentum balance regime near the equator must be different from that in tropics in general.

Figure 9 shows the January zonal momentum balance in the longitude-height cross section, with each term 

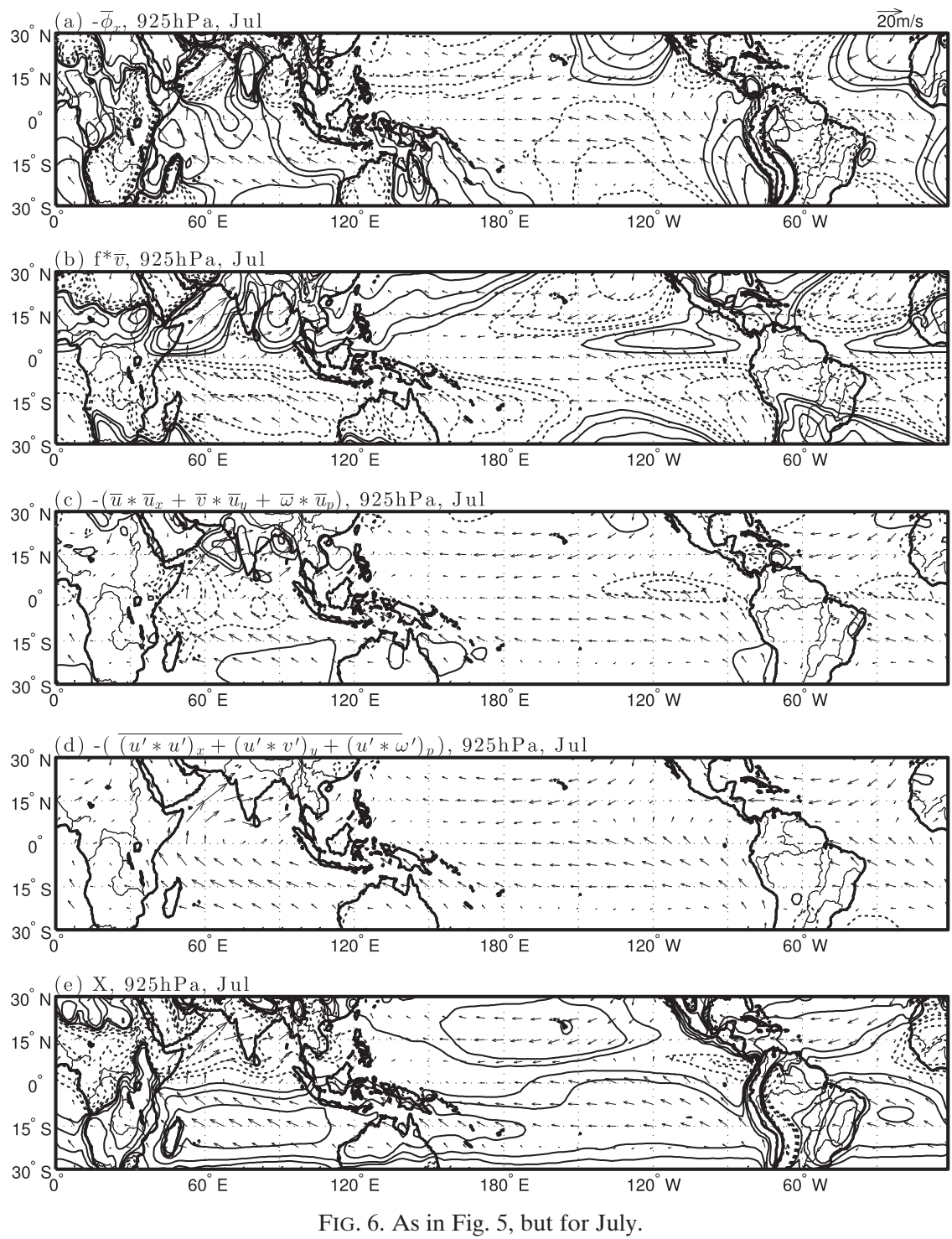

averaged between $5^{\circ} \mathrm{S}$ and $5^{\circ} \mathrm{N}$. In the upper free troposphere, the nonlinear advection term is important at most longitudes to balance the pressure gradient force while the influences of the other two forces are constrained within specific longitude intervals. For example, the transient eddy force contributes to the deceleration of westerlies around $180^{\circ}$ and $130^{\circ} \mathrm{W}$ while the residual force (dominated by CMT) contributes to the deceleration of the easterlies to the west of $160^{\circ} \mathrm{E}$ (the western upper branch of the Walker circulation). Within the ABL, the friction balances the pressure gradient force over all longitudes while the transient eddy force can be neglected. The nonlinear advection term has large values between $30^{\circ} \mathrm{E}$ longitude and $120^{\circ} \mathrm{E}$ longitude, indicating its influence cannot be ignored in these regions.
The July zonal momentum balance in the longitudeheight cross section (Fig. 10) shares similar features to that in January, but with two major differences. First, the nonlinear advection term becomes much stronger near $50^{\circ} \mathrm{E}$ in the ABL, associated with the Somali jet. Second, the transient eddy force becomes weak almost everywhere and there are no regions of large values as in the January case. This can be explained, at least partly, by the fact that the easterlies are prevalent at all longitudes in July and prevent the propagation of midlatitude eddies into the equatorial regions.

\section{Longitudinal-mean zonal momentum balance}

Another case that must differ from the general zonal momentum balance is the zonal-mean zonal momentum 

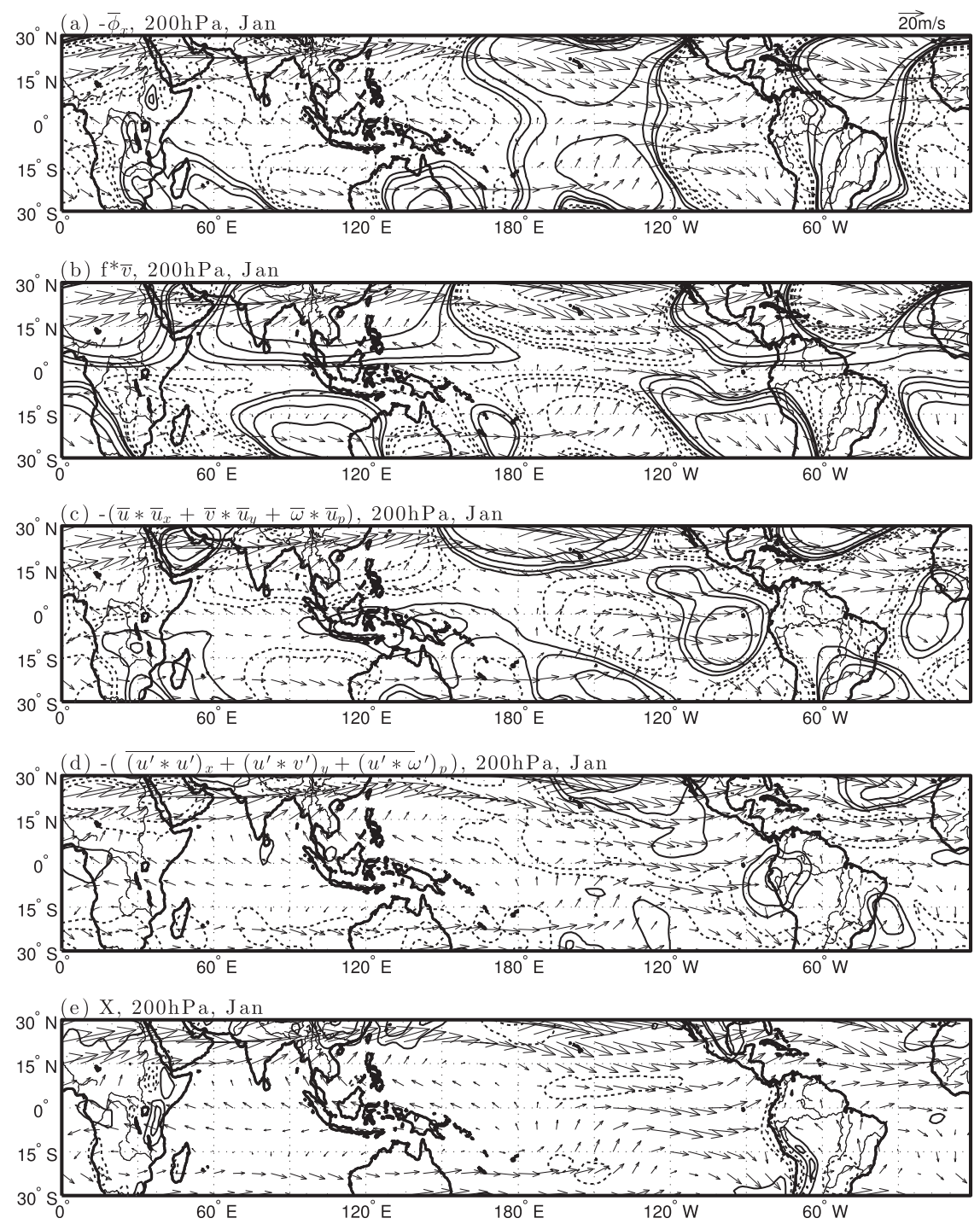

FIG. 7. As in Fig. 5, but at the 200-hPa level.

balance, for which the pressure gradient force becomes zero and the Coriolis force must be balanced by other terms in the zonal momentum equation.

\section{a. The global zonal momentum balance}

One of the most prominent features of the tropical circulation is that the upper-level zonal-mean flows are often dominated by easterlies. Based on the analysis of the zonal-mean zonal momentum balance in the latitude-height cross section in January and July, the zonal-mean zonal momentum balance in the tropics is among the Coriolis force $([f \times \bar{v}])$, the meridional advection $\left(-\left[\bar{v} \times \bar{u}_{y}\right]\right)$, and the residual force $([\mathrm{X}])$. The transient eddy force is weak in the tropics and is anyway positive in the equatorial upper troposphere (Figs. 11a and d), meaning it decelerates the easterlies and so cannot be responsible for maintaining the easterlies in the equatorial upper troposphere. The residual force is important within the ABL and also has positive values around the equatorial upper-troposphere easterlies (Figs. $11 \mathrm{~b}$ and e), which means the residual force is also not responsible for the maintenance of the equatorial uppertroposphere easterlies. Combining the Coriolis force and the meridional advection terms gives a term proportional to the advection of the absolute angular momentum shown in Figs. 11c and f. Although not as strong in the tropical upper troposphere as in the ABL, its negative maximum lies in the middle of the upper-troposphere easterly band, indicating the easterlies are maintained by the absolute angular momentum advection.

There are two major differences between January and July. First, the equatorial upper-troposphere easterlies 

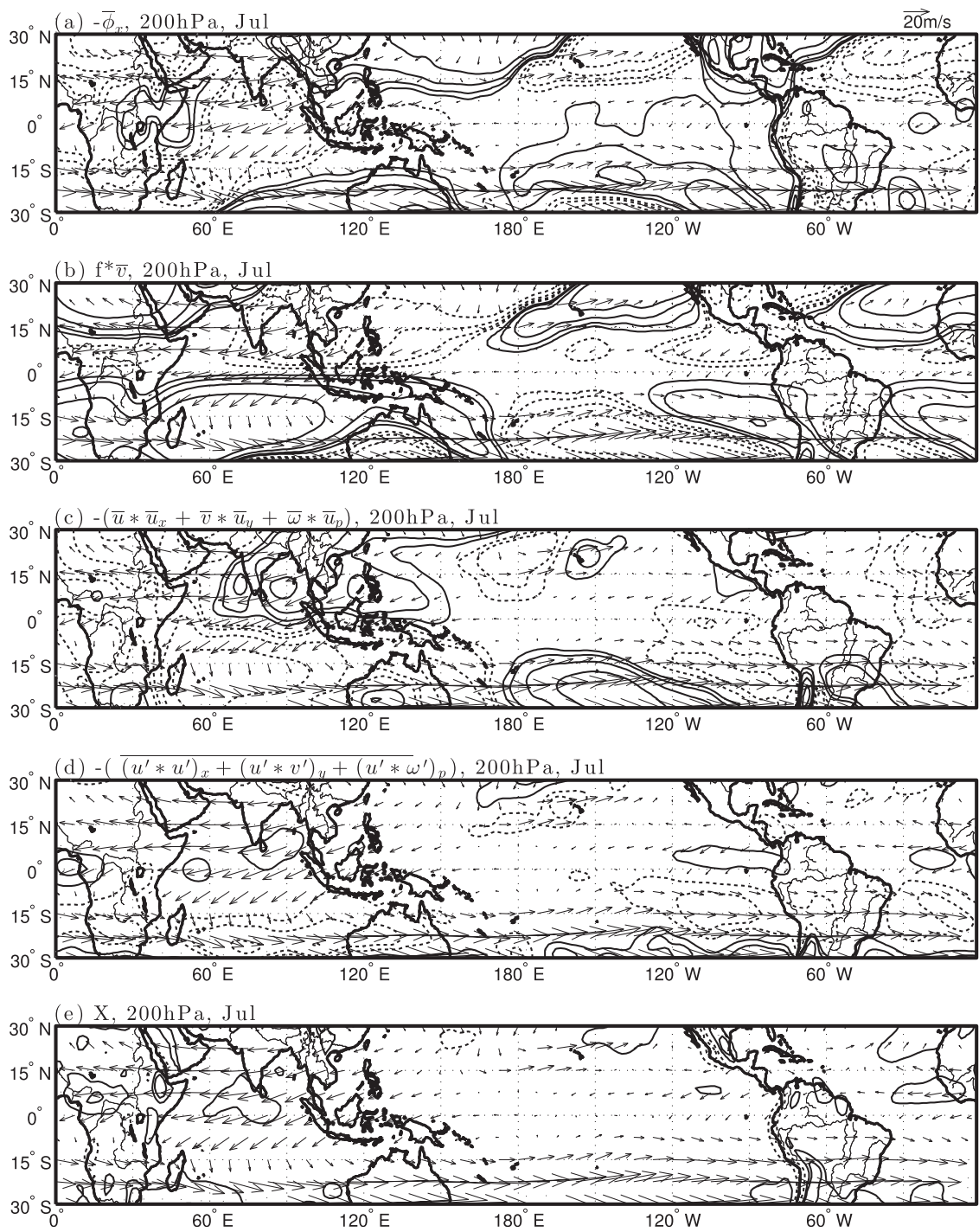

FIG. 8. As in Fig. 5, but at the 200-hPa level and for July.

in July are much stronger than those in January. Second, and consistently, the easterly acceleration by the absolute angular momentum advection is also stronger in July than in January. This covariability between the strength of the easterlies and the absolute angular momentum advection acceleration is consistent with the idea that the advection of absolute angular momentum is responsible for the maintenance of the equatorial uppertroposphere easterlies. It should also be pointed out that the absolute angular momentum advection terms as shown in Figs. 11c and $\mathrm{f}$ are nonlinear and the zonal averages cover the contributions from both the zonal-mean flow $\left\{[\bar{v}] \times\left(f-[\bar{u}]_{y}\right)\right\}$ and the stationary eddies $\left(-\left[\bar{v}^{*} \times \bar{u}_{y}^{*}\right]\right)$. Further analysis reveals that the absolute angular momentum advection is dominated by the zonal-mean part and the stationary eddy influence is secondary and is actually decelerating the easterlies (not shown here).
Therefore, it is the advection of the absolute angular momentum associated with the cross-equatorial zonalmean Hadley circulation that is responsible for the maintenance of the equatorial upper-troposphere easterlies.

\section{b. Momentum balance over the Asian monsoon longitudes}

Because the absolute angular momentum advection in the tropical upper troposphere is proportional to the meridional flow, or the cross-equatorial Hadley circulation, and the strength of the Hadley circulation in July mainly comes from the Asian monsoon contribution, we examine the zonal momentum balance averaged over the Asian monsoon longitudes alone. Unlike the global zonal-mean case, the pressure gradient force becomes important and joins the absolute angular momentum advection as the major accelerating force for the 

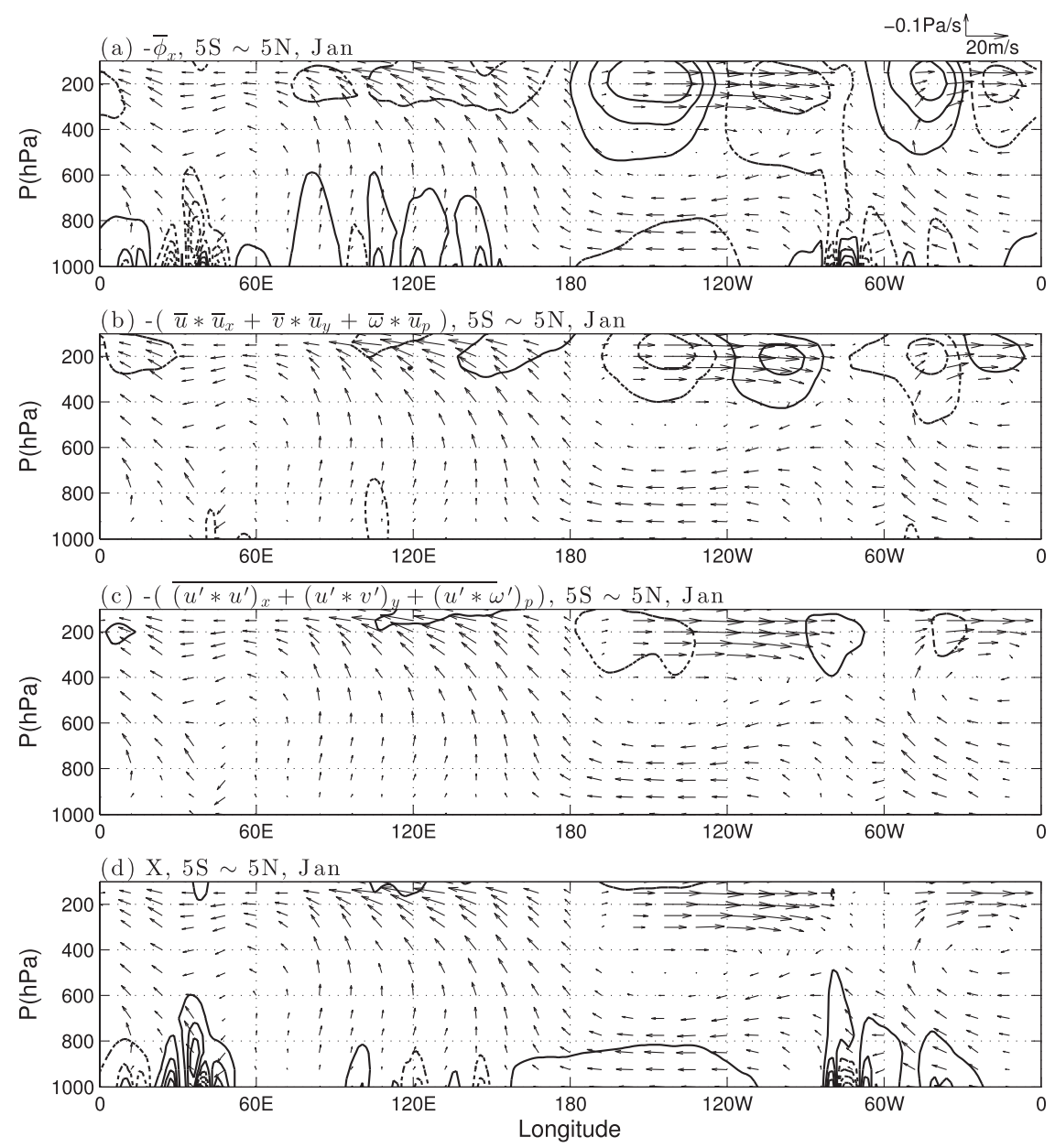

FIG. 9. Multiple-year mean January zonal momentum budget on the longitude-pressure cross section averaged between $5^{\circ} \mathrm{S}$ and $5^{\circ} \mathrm{N}$ (contours). Solid and dashed lines represent positive and negative values, respectively. The smallest positive contour value is $2 \times 10^{-5} \mathrm{~m} \mathrm{~s}^{-2}$ and the contour interval is $4 \times 10^{-5} \mathrm{~m} \mathrm{~s}^{-2}$. Vectors denote circulation on the longitude-pressure cross section. To focus on large-scale features, the traditional 1-2-1 low-pass filter is applied twice in both dimensions for each contour field.

easterlies over the Asian monsoon region. Figures 12a$\mathrm{d}$ show these two accelerating forces in January and July zonally averaged over the longitudes between $60^{\circ}$ and $150^{\circ} \mathrm{E}$, which cover the Asian monsoon longitudes. In January, the acceleration by the absolute angular momentum advection is too weak to maintain the equatorial upper-troposphere easterlies. Instead, the acceleration by the pressure gradient force is much stronger and contributes to the maintenance of the easterlies. In July, the magnitude of the acceleration by the pressure gradient force does not change much from that in January. However, the easterlies become significantly stronger than those in January because the absolute angular momentum advection contributes strongly to the easterly acceleration. Hence the seasonal variability of the equatorial upper-troposphere easterlies over the Asian monsoon region can be explained by the seasonal variability of the absolute angular momentum advection.

\section{c. Momentum balance over the eastern Pacific longitudes}

Another longitude range of particular interest is the eastern Pacific between $130^{\circ}$ and $80^{\circ} \mathrm{W}$, where the tropical upper-troposphere winds change from easterlies in July to westerlies in January. In July, the absolute angular momentum advection maintains the tropical uppertroposphere easterlies (Fig. 13d) while the pressure gradient force actually decelerates the easterlies (not shown). In January, the pressure gradient force still decelerates the tropical upper-troposphere flows, although the flows become westerlies instead of easterlies. At the same time, however, the absolute angular momentum 

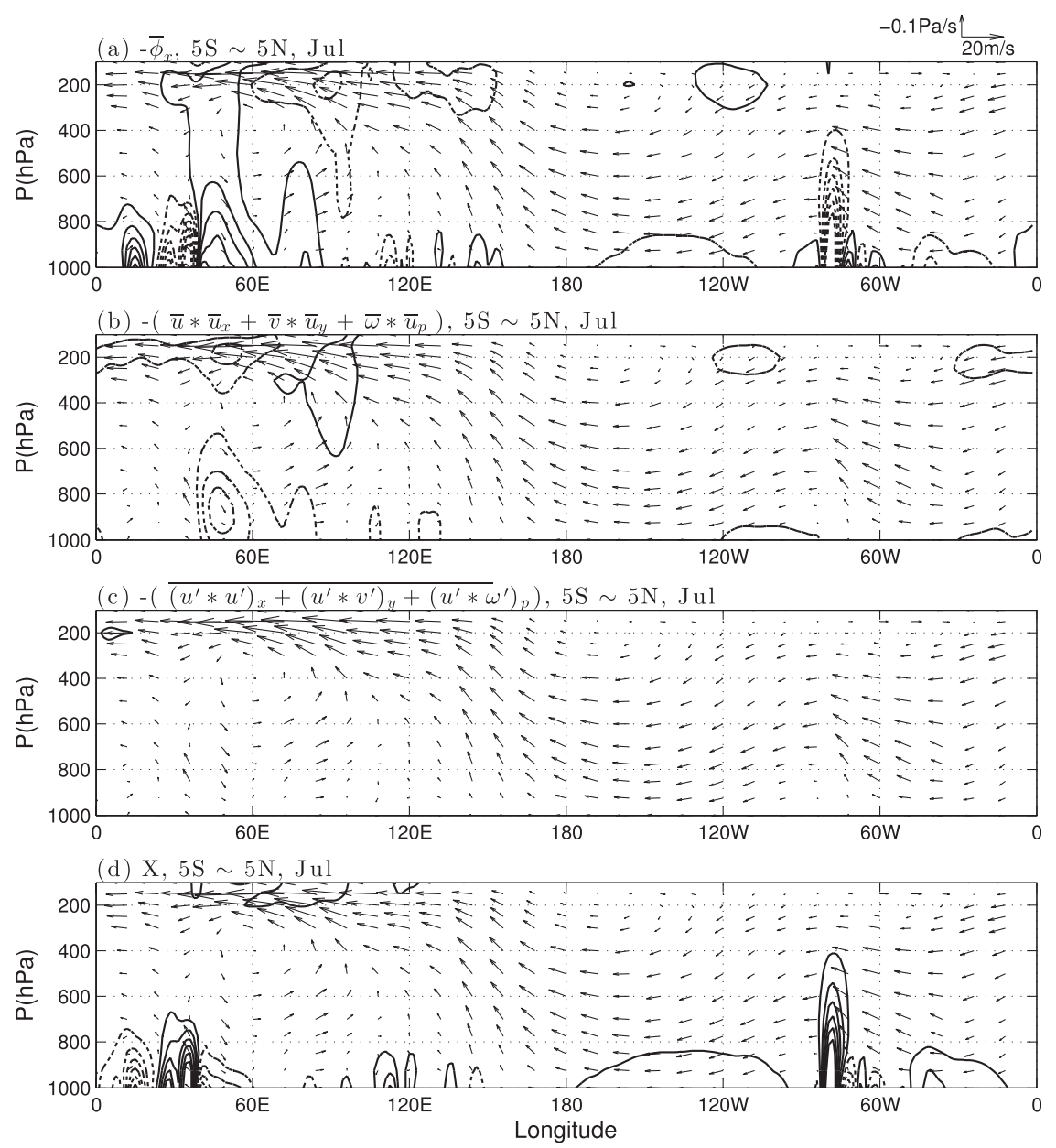

FIG. 10. As in Fig. 9, but for July.

advection becomes extremely weak in the tropical upper troposphere (Fig. 13b) so it cannot maintain the westerlies. So which force is now responsible for maintaining the westerlies in the tropical upper troposphere over the eastern Pacific? Figure 13a shows that it is the zonal momentum advection by the zonal flow or the zonal inertial force. This is also confirmed by the $200-\mathrm{hPa}$ momentum budget (Fig. 7c), which shows the force of the zonal momentum advection by the zonal flow is positive over the eastern Pacific.

\section{Equivalent Rayleigh friction}

In previous sections, it has been shown that the nonlinear advection term is often important in the upper free troposphere and even in some regions within the ABL (e.g., in the Asian summer monsoon region). This poses a challenge to using linear dynamics in the widely used simple tropical atmospheric models. There is, however, the possibility that linear models with Rayleigh friction are still viable if the nonlinear advection term and all other terms not included in the linear dynamics behave collectively in a way that can be approximated by the equivalent Rayleigh friction form. As described in Eq. (8), the equivalent Rayleigh friction coefficients can be estimated at each grid point and the correlation coefficient can be used to assess the appropriateness of the Rayleigh friction approximation (Lin et al. 2008).

Figure 14 shows the equivalent Rayleigh friction coefficients at each grid point at the $925-$ and $200-\mathrm{hPa}$ levels in January and July. Figures $14 \mathrm{a}$ and $\mathrm{b}$ show that the Rayleigh friction coefficients at the 925-hPa level are not uniform over the tropics. The coefficient is much larger over land than over the ocean. Regressing the monthly Rayleigh friction on the zonal flow for all the grid points over all of the multiple years yields a single Rayleigh friction coefficient and a corresponding friction time scale in January (July), which is around 1.2 (1.1) days. For comparison, the Rayleigh friction time scale for the land as a whole and for ocean as a whole in January (July) is 0.5 (0.4) days and 1.5 (1.5) days, respectively; that is, the friction coefficient is 3 times stronger over land. 

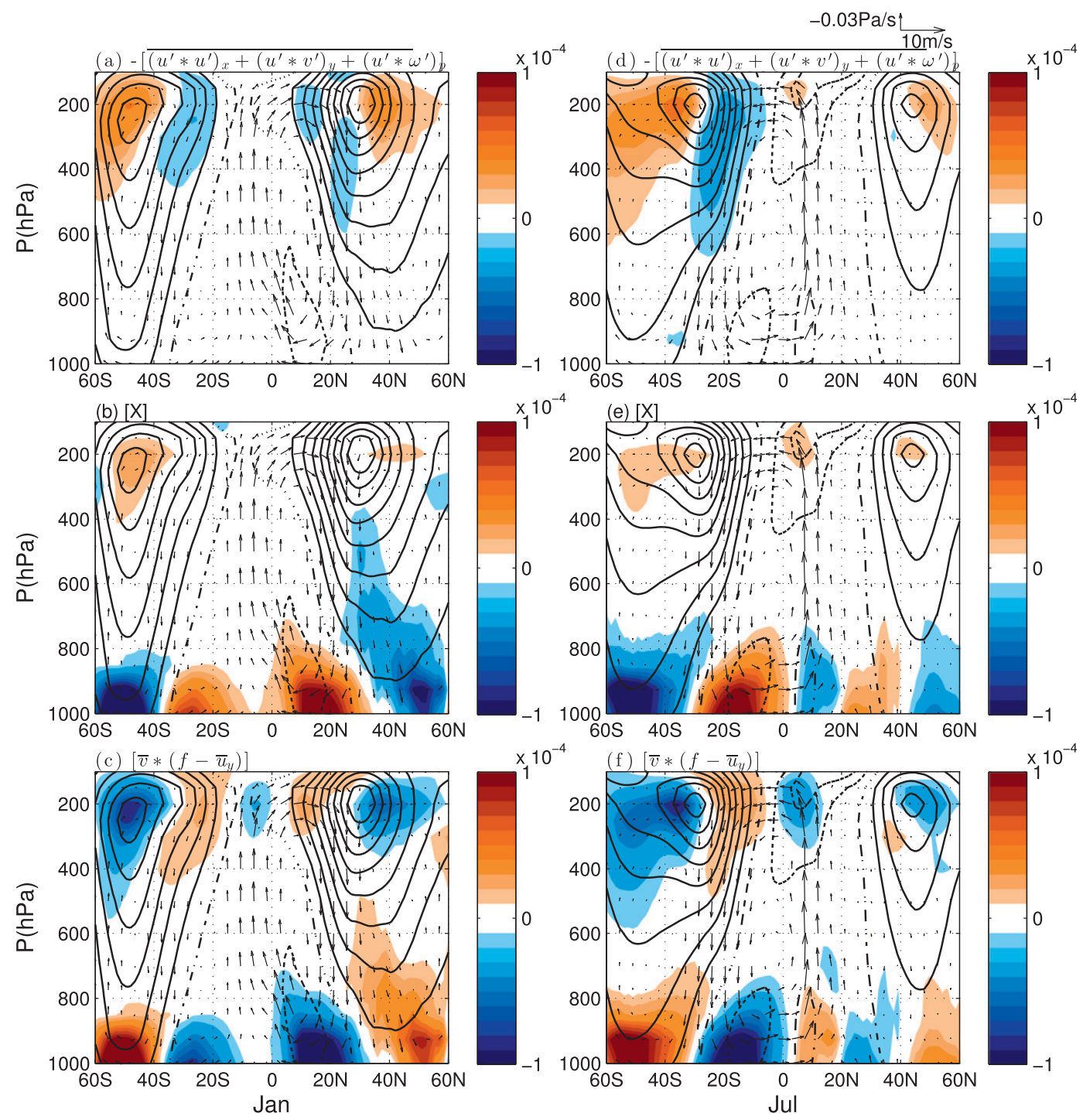

FIG. 11. Multiple-year mean zonal momentum budget on the latitude-pressure cross section zonally averaged over all longitudes (colors): (a)-(c) January and (d)-(f) July. Vectors denote the zonally averaged circulation on the latitude-pressure cross section. Contours represent the zonal-mean zonal flow and the interval is $5 \mathrm{~m} \mathrm{~s}^{-1}$. Solid, dotted, and dashed lines correspond to positive, zero, and negative values, respectively.

Although the linear equivalent Rayleigh friction model does an excellent job in the ABL, it does not perform as well in the tropical upper troposphere. Figures $14 \mathrm{c}$ and $\mathrm{d}$ show the Rayleigh friction coefficients at the $200-\mathrm{hPa}$ level in January and July. The Rayleigh friction coefficients show more inhomogeneity than those at the 925-hPa level and significant areas over the eastern Pacific and the eastern Atlantic in January even show negative friction coefficients. There are locations where the zonal inertial acceleration is important as discussed in section 5. Away from these areas, however, the linear equivalent Rayleigh friction model seems to work better (e.g., the Walker circulation to the west of $120^{\circ} \mathrm{W}$ in
January). Another example is the Asian monsoon circulation, in which the linear equivalent Rayleigh friction model seems to work well and the friction coefficients are in general positive.

Why does the equivalent Rayleigh friction work well in some specific regions but fail in other regions in the upper troposphere? As discussed in previous sections, the nonlinear advection terms are the dominant terms to balance the pressure gradient force and the Coriolis force in the upper troposphere. To make the equivalent Rayleigh friction work, the nonlinear advection terms should decelerate the local flow in the zonal direction, which is equivalent to say that the flow, along its streamline, 

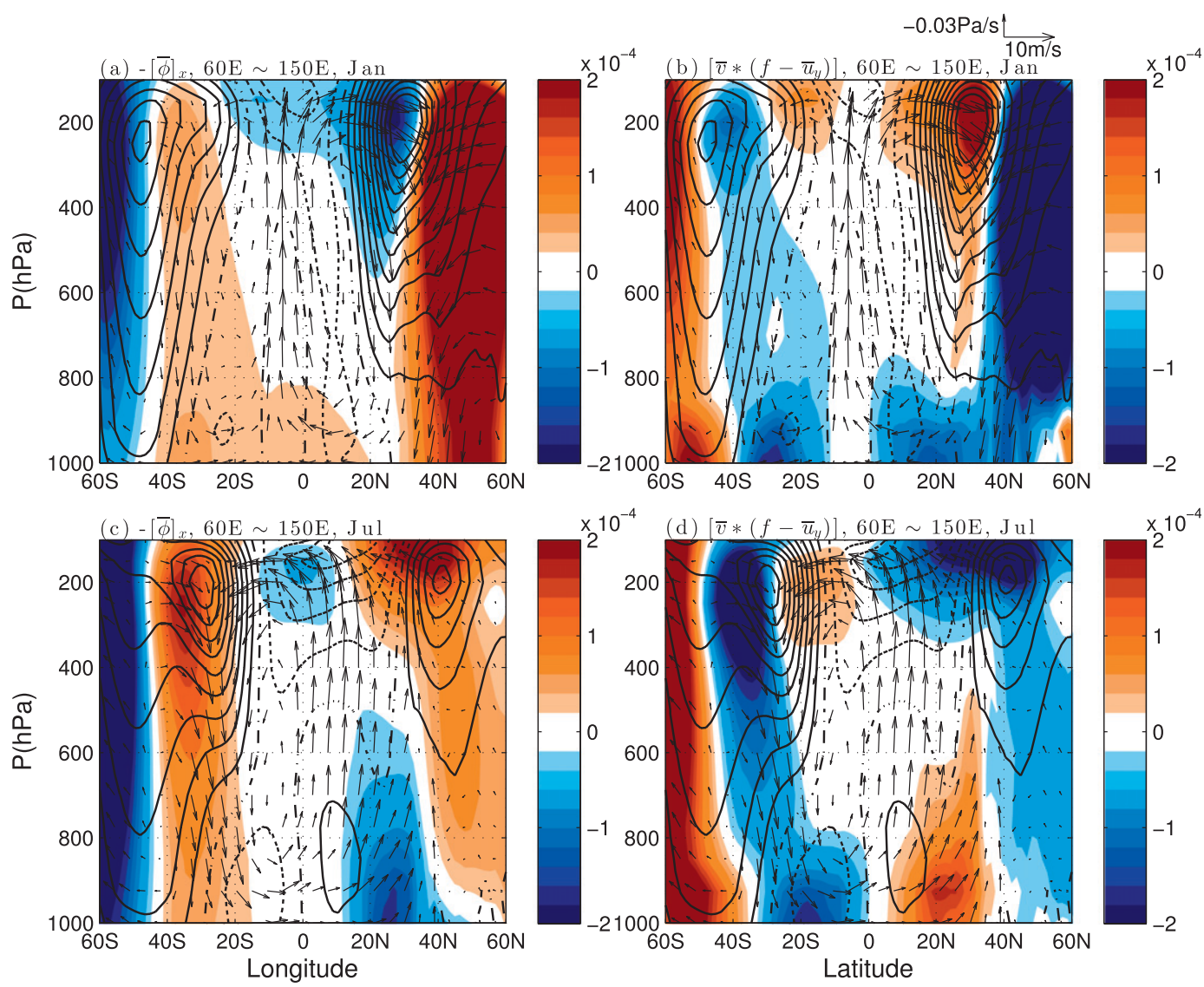

FIG. 12. As in Fig. 11, but the zonal momentum budget terms are averaged over the Asian monsoon region instead of all longitudes.

should increase in absolute zonal velocity. There are two types of regions in the upper troposphere satisfying this condition: 1) flows near the divergent-outflow regions of the Asian monsoon and the North American monsoon in July and of the Walker circulation in January, and 2) cross-equator flows after turning their zonal direction (e.g., the Asian monsoon flows to the south of $15^{\circ} \mathrm{S}$ in July). Correspondingly, there are also two types of upper-troposphere regions that do not satisfy the condition 1) regions of zonal convergence such as over the tropical eastern Pacific and eastern Atlantic, and 2) crossequator flows before turning their zonal direction such as the Asian monsoon flows between $0^{\circ}$ and $15^{\circ} \mathrm{S}$.

\section{Conclusions and discussion}

ERA-Interim daily data have been used in this study to examine the three-dimensional zonal momentum balance of the tropical atmospheric circulation in both January and July, which represent the mature global monsoon months in the Southern Hemisphere and Northern Hemisphere, respectively. We also do all the calculations with the NCEP-NCAR reanalysis dataset (Kalnay et al. 1996) and find no significant difference between the two reanalysis datasets. The following conclusions have been reached:

- In the atmospheric boundary layer (ABL), the pressure gradient force, the Coriolis force, and surface friction are the dominant terms in the zonal momentum balance. The nonlinear advection term is important only in the Asian summer monsoon region. Linear dynamics is a good approximation for the zonal momentum equation within the $\mathrm{ABL}$ yet the equivalent Rayleigh friction coefficient is not spatially uniform. In general, the coefficient over the land is 3 times larger than that over the ocean.

- In the upper troposphere, the dominant terms in the zonal momentum balance are the pressure gradient force, the Coriolis force, and the nonlinear advection term. The linear dynamics approximation is not as good as that in the ABL but still is applicable in regions such as the Walker circulation and the Asian monsoon region. 

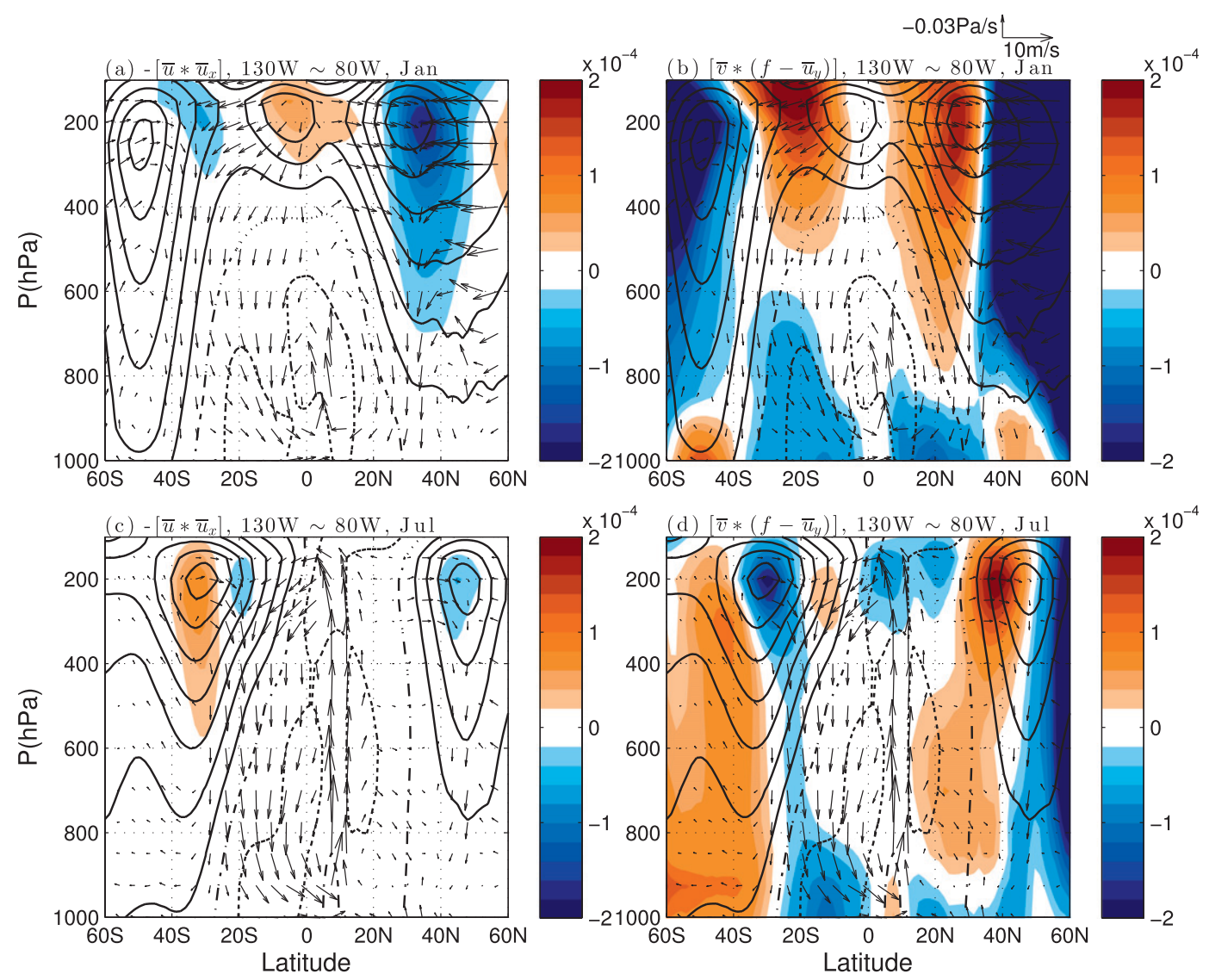

FIG. 13. As in Fig. 11, but the zonal momentum budget terms are averaged over the eastern Pacific region instead of all longitudes.

- Near the equator, where the Coriolis force is small, the zonal momentum balance is in general among the pressure gradient force, the nonlinear advection, and the residual force (dominated by friction in the $\mathrm{ABL}$ and by the CMT in the free troposphere). The transient eddy force is in general secondary but becomes important in the longitudes with upper-troposphere equatorial westerlies in January.

- The absolute angular momentum advection associated with the cross-equatorial Hadley circulation plays an important role in maintaining the global zonal-mean equatorial upper-troposphere easterlies and its change of strength between January and July also explains the intensity of the easterlies. The absolute angular momentum advection also has an influence on regional zonal flows; that is, it strengthens the Asian monsoon easterlies from January to July and shifts the equatorial upper-troposphere flow over the eastern Pacific from westerlies in January to easterlies in July.

Lin et al. (2008) showed that the mechanical damping in the Gill-type models for the annual mean Walker circulation consists of two sources: the nonlinear advection and the residual force. Our study shows that the transient eddy force is also important in the eastern upper branch of the Pacific Walker circulation in January when the westerlies dominate there and allow midlatitude eddies to propagate to the equator. The transient eddy force might be neglected in the annual mean zonal momentum balance but can be important in particular months. Schneider and Bordoni (2008) demonstrated that eddy-mean flow interaction plays an important role in the seasonal cycle of the Hadley circulation, which also implies that the transient eddy force, although negligible in the annual mean circulation, can be important in the seasonal cycle.

The mechanisms for the dominance of the easterlies in the equatorial upper troposphere have been explored in Lee (1999) and Kraucunas and Hartmann (2005). Although the stationary wave associated with zonal asymmetric heating tends to drive a superrotational flow (westerlies) over the equatorial upper troposphere, the easterly acceleration associated with the crossequatorial Hadley circulation often overwhelms this 

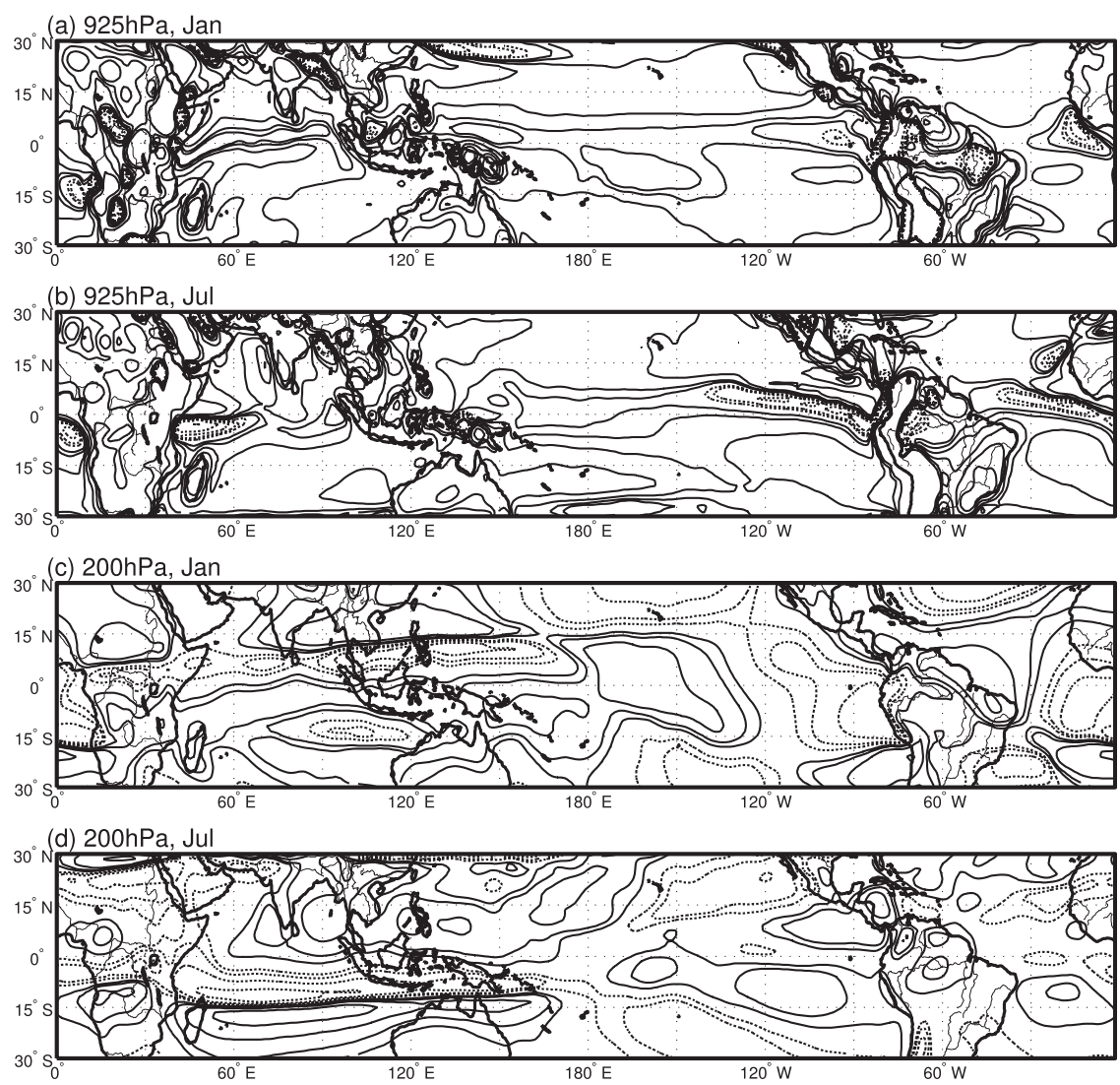

FIG. 14. Rayleigh friction coefficient calculated based on regression. The contour values are $(-6.4,-3.2,-1.6,-0.8,-0.4,-0.2,0.2,0.4,0.8,1.6,3.2,6.4) \times 10^{-5} \mathrm{~s}^{-1}$. Solid and dashed lines represent positive and negative values, respectively. To focus on large-scale features, the traditional 1-2-1 low-pass filter is applied twice in both dimensions for each contour field.

effect and drives the observed dominant easterlies. Our study confirms this point and shows that the absolute angular momentum advection indeed maintains the zonal-mean easterlies in the equatorial upper troposphere while the stationary wave force has a westerly tendency but is much smaller. As the absolute angular momentum advection arises from the cross-equatorial Hadley circulation, which is controlled by the off-equator heating (Lindzen and Hou 1988), the easterly acceleration by the absolute angular momentum advection varies seasonally as the heating center moves north and south. Because the cross-equatorial Hadley circulation is stronger in the Northern Hemisphere summer than in the Southern Hemisphere summer, the easterly acceleration by the absolute angular momentum advection is stronger in the Northern Hemisphere summer and results in more intense upper-troposphere equatorial easterlies. Although the westerly acceleration by the equatorial stationary waves has a similar pattern of seasonal variability as the easterly acceleration by the zonalmean meridional flow (Dima et al. 2005), its magnitude is much smaller than the easterly acceleration. Therefore, the prevalence of the tropical upper-troposphere easterlies and the variability of their strength are determined by the zonal-mean Hadley circulation and the associated absolute angular momentum advection.

We also extend this idea to the maintenance and seasonal variability of regional zonal flows and find that the variability of the strength of the Asian monsoon region easterlies and the shift of the direction of zonal flow over the eastern Pacific between January and July can be explained by the variability of the absolute angular momentum advection associated with the crossequatorial Hadley circulation. This is relevant to the interaction of the meridional Hadley circulation and the zonal Walker circulation-the two preeminent circulation systems in the tropics. Future work will examine this interaction on other time scales and its impact on climate in the tropics and extratropics.

Acknowledgments. This work was supported by National Science Foundation Award ATM 08-04107 and 
National Oceanographic and Atmospheric Administration Award NA10OAR4310137 [Global Decadal Hydroclimate Variability and Change (GLODecH)].

\section{REFERENCES}

Adler, R. F., and Coauthors, 2003: The version-2 Global Precipitation Climatology Project (GPCP) monthly precipitation analysis (1979-present). J. Hydrometeor., 4, 1147-1167.

Carr, M., and C. Bretherton, 2001: Convective momentum transport over the tropical Pacific: Budget estimates. J. Atmos. Sci., 58, 1673-1693.

Chiang, J., and S. Zebiak, 2000: Surface wind over tropical oceans: Diagnosis of the momentum balance, and modeling the linear friction coefficient. J. Climate, 13, 1733-1747.

Davey, M., and A. Gill, 1987: Experiments on tropical circulation with a simple moist model. Quart. J. Roy. Meteor. Soc., 113, 1237-1269.

Dee, D., and Coauthors, 2011: The ERA-Interim reanalysis: Configuration and performance of the data assimilation system. Quart. J. Roy. Meteor. Soc., 137, 553-597.

Deser, C., 1993: Diagnosis of the surface momentum balance over the tropical Pacific Ocean. J. Climate, 6, 64-74.

Dima, I., J. Wallace, and I. Kraucunas, 2005: Tropical zonal momentum balance in the NCEP reanalyses. J. Atmos. Sci., 62, 2499-2513.

Fu, X., and B. Wang, 1999: The role of longwave radiation and boundary layer thermodynamics in forcing tropical surface winds. J. Climate, 12, 1049-1069.

Gill, A., 1980: Some simple solutions for heat-induced tropical circulation. Quart. J. Roy. Meteor. Soc., 106, 447-462.

Huffman, G. J., R. F. Adler, D. T. Bolvin, and G. Gu, 2009: Improving the global precipitation record: GPCP version 2.1 . Geophys. Res. Lett., 36, L17808, doi:10.1029/2009GL040000.
Kalnay, E., and Coauthors, 1996: The NCEP/NCAR 40-Year Reanalysis Project. Bull. Amer. Meteor. Soc., 77, 437-471.

Kraucunas, I., and D. Hartmann, 2005: Equatorial superrotation and the factors controlling the zonal-mean zonal winds in the tropical upper troposphere. J. Atmos. Sci., 62, 371-389.

Lee, S., 1999: Why are the climatological zonal winds easterly in the equatorial upper troposphere? J. Atmos. Sci., 56, 13531363.

Lin, J., B. Mapes, and W. Han, 2008: What are the sources of mechanical damping in Matsuno-Gill-type models? J. Climate, 21, 165-179.

Lindzen, R., and S. Nigam, 1987: On the role of sea surface temperature gradients in forcing low-level winds and convergence in the tropics. J. Atmos. Sci., 44, 2418-2436.

— heating centered off the equator. J. Atmos. Sci., 45, 2416-2427.

Matsuno, T., 1966: Quasi-geostrophic motions in the equatorial area. J. Meteor. Soc. Japan, 44, 25-42.

Neelin, J., 1989: On the interpretation of the Gill model. J. Atmos. Sci., 46, 2466-2468.

Schneider, T., and S. Bordoni, 2008: Eddy-mediated regime transitions in the seasonal cycle of a Hadley circulation and implications for monsoon dynamics. J. Atmos. Sci., 65, 915934.

Seager, R., 1991: A simple model of the climatology and variability of the low-level wind field in the tropics. J. Climate, $\mathbf{4}$, 164-179.

Suarez, M. J., and D. G. Duffy, 1992: Terrestrial superrotation: A bifurcation of the general circulation. J. Atmos. Sci., 49, 15411554.

Wang, B., and T. Li, 1993: A simple tropical atmosphere model of relevance to short-term climate variations. J. Atmos. Sci., 50, 260-260.

Zebiak, S., 1990: Diagnostic studies of Pacific surface winds. J. Climate, 3, 1016-1031. 